RUNNING HEAD: Being blamed

Guilt in Response to Blame from Others

Brian Parkinson and Sarah Illingworth

Oxford University

Please address correspondence to:

Brian Parkinson

Department of Experimental Psychology

South Parks Road

Oxford OX1 3UD

UK 


\begin{abstract}
In three studies, participants rated appraisals and emotions associated with situations in which someone else blamed them for something that was not their fault. Although the instructions made no reference to guilt, several participants spontaneously reported experiencing this emotional reaction in all three studies. Using event-contingent diaries, study 1 found that rated self-blame appraisals were only weakly correlated with reported guilt when blame was directed at participants without good reason. Using directed retrospective recall, study 2 found that guilt was higher in a blamed than an unblamed condition and that the desire to apologise reliably predicted guilt even after controlling for all appraisals relating to self-blame in the blamed condition. Study 3 again used retrospective recall but included an orthogonal manipulations of self-blame and blame from others. Guilt was significantly higher in blamed conditions when self-blame was low, but not when it was high. These findings show that self-blame is often but not always a strong predictor of guilt and other relational variables sometimes contribute independently to this emotion. Under certain circumstances, guilt can arise in response to someone else's blame even when there is little or no self-blame. Thus, the relationship between self-blame and guilt may be variable rather than determinate.
\end{abstract}

Key words: guilt, self-blame, appraisal, emotion, relationship repair 


\section{Guilt in Response to Blame from Others}

Different emotions are associated with different relational meanings (e.g., Roseman, 1979; Smith \& Ellsworth, 1985). For example, anger tends to imply that you blame someone else for something that has gone wrong, whereas guilt suggests that you blame yourself. According to some versions of appraisal theory (e.g., Lazarus, 1991; Smith \& Lazarus, 1993, but not all, e.g., Kuppens, Van Mechelen, Smits, \& De Boeck, 2003; Roseman, 2001), subjective apprehension of these relational meanings fully determines the quality of the experience in advance. In other words, what makes you feel guilt instead of another emotion is the prior perception that you are personally accountable for some unwanted outcome. But is this the only possible route to guilt? Does every instance of this emotion entirely depend on antecedent self-blame or might this relational meaning instead represent how other people interpret the presentation of guilt further downstream? In interpersonal situations does the initial attribution of responsibility to the self necessarily come from within, or can guilt also be provoked by someone else's blame before or even without self-blame appraisals? The present paper is intended to address this latter possibility from the perspective of a socialrelational approach to emotions (e.g., Parkinson, Fischer, \& Manstead, 2005).

Little support for guilt's exclusive dependence on self-blame appraisals is provided by the low to moderate correlations typically found in questionnaire-based studies (e.g., Bennett, Lowe, \& Honey, 2003; Frijda, Kuipers, \& ter Schure, 1989; Smith \& Lazarus, 1993). Further, these correlations are often based on retrospective self-reports that may be biased in favour of an appraisal account (Parkinson, 1997). For example, cuing recall with the word "guilt" (or with situation descriptions carrying implicit guilt connotations) is likely to activate stereotypical representations of this emotion that may already feature personal accountability as its assumed cause (e.g., Russell, 1987; Parkinson \& Manstead, 1992). Correspondingly, when reconstructing emotional memories in the context of psychological experiments, 
participants may often focus on examples that are readily understandable and justifiable. These particular instances of emotion are especially likely to conform to the rationalistic predictions of appraisal theory. Indeed, Parkinson (1999) found that ratings of selfaccountability and self-blame were significantly lower when participants were explicitly instructed to recall "unreasonable" rather than "reasonable" guilt episodes.

Further evidence of variability in associations between guilt and self-accountability can also be found outside the appraisal literature. For example, the commonly observed phenomena of "survivor guilt" (e.g., Niederland, 1961) and "victim guilt" (e.g., Lamb, 1986) suggest that people sometimes feel guilty about events for which someone else is clearly to blame (see Baumeister, Stillwell, \& Heatherton, 1994). Similarly, Kroon (1988, cited in Frijda, 1993) found that only $28 \%$ of participants describing strong experiences of guilt considered themselves to have caused the event that provoked the emotion.

Some theorists have argued that guilt operates as a function of interpersonal dynamics rather than purely intrapsychic processes (e.g., Barrett, 1995; Baumeister, Stillwell, \& Heatherton, 1994; Parkinson, Fischer, \& Manstead, 2005). Indeed, an ontogenetic precursor of adult forms of guilt may be empathic distress as experienced when infants witness the suffering of close others (Hoffman, 1982). Along related lines, Emde, Johnson, and Easterbrooks (1987) identified "hurt feelings" arising in response to parental disapproval as forerunners of more articulated guilt reactions. It therefore seems possible that children are socialised into feeling guilty and thereby acknowledging blame for their conduct partly as a function of prior interpersonal experiences of this kind (cf. Barrett, 1995; Zahn-Waxler \& Kochanska, 1990). In other words, guilt-like emotional reactions (or precursors of guilt) may be present in early experience before any association with self-blame has developed. A common assumption is that self-blame supersedes these more basic relational dynamics once socialization is complete. Instead, our contention is that people may continue to respond with 
guilt-like emotion throughout their lives when someone close is perceived as blaming them, even when they come to learn that this is not a reasonable reaction.

Interpersonal approaches to adult guilt have emphasised the emotion's social function as a mode of apology or reparation instead of seeing the emotion simply as a response to privately apprehended self-blame (e.g., Barrett, 1995; Baumeister, Stillwell, \& Heatherton, 1994). Consistent with this reasoning, O’Malley and Greenberg (1990) found that female participants allocated smaller fines to motorists who expressed remorse after a hypothetical accident. The basic idea is that feeling bad about something demonstrates your sensitivity to the other person's concerns, as well as equalizing the degree of suffering experienced by both of you. Thus, the presentation of guilt shows the other that you want to put things right for him or her.

If guilt's primary purpose is to serve such relational functions, someone else's perception that they deserve recompense from you may be sufficient to induce this emotion, regardless of whether you personally feel responsible for what has happened. For example, Millar and Tesser (1988) found that estimated guilt after lying about a transgression was independently predicted by the perceived expectations of the recipient of the lie, after having controlled for own expectations. Further, some of Baumeister, Stillwell, and Heatherton's (1995) participants reported feeling guilty even in response to others' accusations that they thought to be exaggerated. Similarly, Berndsen, van der Pligt, Doosje, and Manstead (2004) found that more intense guilt was attributed to protagonists in narrative vignettes under higher levels of interpersonal harm even when the protagonists were presented as evaluating their own actions favorably. An even clearer case of this phenomenon was provided by one of Parkinson's (1999) participants who wrote that she felt guilty when a "friend had a go at me over something she accused me of telling someone else that should have remained confidential." In fact she "hadn't said anything" (pp. 377-378). 
Participants in Parkinson's (1999) study were specifically told to recall unreasonable instances of guilt. One problem with this procedure is that self-reports may have been tailored to meet the perceived requirement of the experimental instructions. If participants believed that self-blame provides reasonable grounds for experiencing guilt, they may have felt obliged to minimize any acknowledgement of personal accountability and to emphasise instead the interpersonal dynamics as a way of meeting the stated requirement for unreasonable instances of the emotion. The present series of studies attempted to solicit comparable reports of guilt even when these potential demand characteristics are removed. We used instructions that made no direct reference to guilt and instead cued situations expected (on the basis of the arguments above) to be likely interpersonal occasions for unreasonable guilt. In particular, we asked participants to report occasions on which someone else blamed them for something that was not their fault. Guilt in response to these situations was then rated by participants as only one of a variety of possible emotional reactions.

The overall aim of the present studies was to investigate whether guilt can arise in situations where someone close blames you for something even when you do not blame yourself. We predicted that moderate levels of guilt feelings would be reported by some participants even when their rated self-accountability was low, suggesting that this appraisal is not a necessary condition for the experience of guilt. However, we did not expect guilt to be an inevitable response to being blamed across all participants. Clearly, people often react to accusations with anger and other antagonistic emotions. Our prediction was that the level of guilt experienced in response to being blamed would depend on the extent to which participants were motivated to repair the relationship with the other person, even after controlling for possible effects of self-blame. 


\section{Study 1}

Study 1 used a diary method to investigate situations of interpersonal blame. Its aim was to assess the extent to which people in everyday situations would spontaneously report guilt when blamed for something they had not done. The focus on guilt was concealed by asking participants to record all situations in which they had blamed someone close to them as well as situations in which someone close to them had blamed them with or without good reason. Our central prediction was that guilt would sometimes be the reported reaction to someone else's unreasonable blame and that its occurrence would not depend exclusively on feeling personally to blame for what happened. However, we also expected participants to report guilt more consistently in incidents when the other person's blame was perceived as reasonable, because in these cases, participants are more likely to experience self-blame (and an absence of other-blame) in addition to blame from the other.

\section{Method}

Participants. 21 female and 9 male UK University students aged between 18 and 24 took part in this study.

Procedure. Participants were provided with a diary questionnaire on which they were asked to record every incident over the following 14 days when they felt blamed by someone close to them. For each recorded incident, they recorded whether the other was blaming them with or without good reason, and used a 9-point scale (with 1 meaning "none at all" and 9 meaning "very much") to rate their levels of six emotions (sadness, surprise, disappointment, anger, pride, and guilt ${ }^{1}$ ) and appraisals of self-blame for the event they were being blamed for ("to what extent did you feel to blame"). Completed questionnaires were returned anonymously in sealed envelopes. 


\section{Results}

Twenty-five participants recorded at least one incident of both reasonable and unreasonable blame over the study period. Because the number of instances reported by each of these participants was not great enough to permit multilevel modelling (e.g., Raudenbush \& Bryk, 2002), the subsequent analyses focus on within-subjects comparisons between the first of each kind of reported incident for these 25 participants (i.e, one reasonable and one unreasonable blame incident per participant).

Self-blame. As predicted, participants reported their level of self-blame as significantly higher when the other's blame was reasonable $(M=6.58, S D=2.04)$ than when it was unreasonable $(M=3.13, S D=2.01, t(23)=6.87, p<.001)$.

Emotions. The mean level of guilt reported in response to reasonable blame was significantly higher $(M=5.64, S D=2.55)$ than that reported in response to unreasonable blame $(M=3.44, S D=2.04, t(24)=3.54, p=.002)$. Although the average level of guilt in the unreasonable blame condition was comparatively low, it differed significantly from zero $(t(24)=8.42, p<.001)$, and 6 out of 25 participants reported guilt above the midpoint of the scale. In other words, the mean in the unreasonable blame condition does not reflect a consistently weak guilt reaction, but rather variable levels of guilt including some relatively strong reactions. Examples of reported unreasonable guilt at high levels coupled with low self-blame are presented in Table 1 . The only other emotion reported at significantly different levels for the two incidents was surprise, which was higher in the unreasonable blame condition $(M=4.64, S D=2.46)$ than in the reasonable blame condition $(M=3.32, S D$ $=2.41, t(24)=2.55, p=.018)$. None of the mean emotion scores were above the midpoint of the scale. Surprise and guilt showed near-zero, non-significant correlations in both the unreasonable $(r(24)=-.050, p=.812)$ and reasonable blame conditions $(r(24)=.033, p=$ $.875)$. 
Correlations between self-blame and guilt. Self-blame showed a moderate and significant positive correlation with guilt in the reasonable blame condition $(r(24)=.581, p=$ .002). In the unreasonable blame condition, however, the correlation between self-blame and guilt was small and non-significant $(r(24)=.110, p=.608)$.

\section{Discussion}

Study 1 provided an initial demonstration that people sometimes spontaneously report guilt in response to situations in which someone else blames them for something without good reason. Unlike in Parkinson's (1999) study, these participants were not told to generate examples of guilt but to rate their emotional experience in response to being blamed. It is therefore difficult to explain these findings in terms of demand characteristics associated with specific requests for unreasonable guilt. If anything, the instruction to report on emotions experienced in response to someone else's unreasonable blame might be interpreted as implying angry rather than guilty reactions. Thus, the most likely explanation for participants' spontaneous guilt reports is that they genuinely felt guilty in response to another's blame.

The guilt reported by some participants when blamed unreasonably by someone close to them was not closely related to reported self-blame suggesting that this appraisal cannot fully explain the emotional reaction. It therefore seems unlikely that blame from another person can only lead to guilt by increasing perceptions of being blameworthy.

However, as predicted, participants were more likely to report guilt in response to reasonable blame than unreasonable blame, and in this condition the intensity of the emotion was positively correlated with self-blame. These results confirm that guilt is often associated with higher self-blame as predicted by many theories (e.g., Roseman, 2001; Tangney \& Dearing, 2002; Tracy \& Robins, 2006), but not that guilt always and exclusively depends on self-blame as certain appraisal models contend (e.g., Smith \& Lazarus, 1993). Instead, the 
strength of the self-blame-guilt association varies systematically depending on the nature of the interpersonal situation (see Kuppens et al., 2003; Parkinson, Roper, \& Simons, in press, for similar arguments regarding anger).

\section{Study 2}

Although study 1 demonstrated that participants sometimes report guilt when close others blame them without good reason, there was no direct evidence that this effect specifically depended on being blamed rather than simple exposure to someone else's suffering. Study 2 therefore used a directed retrospective recall methodology to solicit reports of incidents in which another person blamed and did not blame participants for comparable unwanted events. Any differences in guilt between these conditions should be a consequence of others' blame rather than their perceived suffering. Because the retrospective recall procedure lifts some of the constraints on questionnaire length necessarily associated with diary research, additional measures relating to relational motivations and other appraisals that are potentially associated with guilt could also be included.

The appraisal measures used in this study were taken from Smith and Lazarus's (1993) influential research. According to their model, emotion depends on motivational relevance (the extent to which what is happening, or has happened, impacts on current concerns), unpleasant emotion additionally depends on motivational incongruence (how much what is happening, or has happened, interferes with current concerns), and guilt additionally depends on self-accountability (assessing how responsible the individual feels for what is happening or has happened). Whenever a transaction is appraised as high on all three of these dimensions, guilt should automatically ensue. Without these appraisals, Smith and Lazarus (1993) suggest that guilt cannot occur.

Our central prediction was that guilt would be rated at higher levels in situations when another person blamed the participant for something that had happened to them than in 
comparable situations when blame was directed elsewhere. Further, we expected some participants to spontaneously report moderate to high levels of guilt in response to another's unjustified blame, even when self-accountability was rated as low. Finally, we predicted that guilt ratings would be correlated with the reported motivation to repair the relationship even after controlling for self-accountability, motivational congruence, and motivational relevance.

\section{Method}

Participants. Nine female and five male undergraduate psychology students aged between 20 and 34 completed the study at the beginning of a compulsory practical class.

Procedure. Participants were given a questionnaire headed "emotional responses to perceived blame." The instructions explained that the study concerned possible reactions to disapproval when that disapproval was directed either at the self or other people. Participants were told to focus on situations where they felt broadly sympathetic towards the person doing the blaming. Each participant reported on two separate incidents (in counterbalanced order). For the blamed condition, the required situation was specified as follows: "please try to remember a situation when you became aware that someone close to you specifically blamed you for something that affected them adversely, and although it was actually not your fault you still felt sympathetic towards them." For the unblamed (control) condition, participants were asked to recall a situation in which the other person did not know who was to blame for something that affected them adversely but knew that it was not the participant.

Measures. Participants first reported how long ago incident 1 had occurred, and provided a brief open-ended description of what had happened. Next, they rated how easily they had been able to remember a suitable incident, how good an example of the requested kind of incident it was, to what extent the other privately blamed them, to what extent the other overtly blamed them, and to what extent they had anticipated that the other would blame them in the future. 
The next items were based directly on those used by Smith and Lazarus (1993) to measure the appraisal dimensions proposed to differentiate qualitatively distinct emotions. The three putatively guilt-relevant items were: motivational relevance ("How important was what was happening in this situation to you?"); motivational incongruence (“Think about what you DIDN'T WANT in this situation. To what extent were those UNDESIRABLE elements present?"); and self-accountability (“To what extent did you consider YOURSELF to be responsible for this situation?"). The other appraisal dimensions assessed were motivational congruence, self-accountability, future expectancy, problem-focused coping potential, and emotion-focused coping potential.

Three items assessed relational motivations: relationship repair ("To what extent did you feel that you wanted to put things right between you and the other person?"); interpersonal emotion repair ("To what extent did you feel that it was your duty to make the other person feel better about what had happened (or was happening)?"); and making amends (“To what extent did you feel that you wanted to make amends to the other person?"). Participants were also asked to rate the extent to which they could sympathise with the other person's perspective. In all cases, the context made it clear that the specified "other person" was the close other who had suffered the negative event.

Finally, participants rated the extent to which they were experiencing the full range of emotions sampled by Smith and Lazarus (1993) as described by the 34 separate adjectives ${ }^{2}$ used by these investigators, including the key dependent measure: "guilty." The main purpose of the other emotion items was to disguise the fact that this particular emotion was the study's central focus to minimize demand characteristics (see above) ${ }^{3}$. Items were rated using an 11-point scale ranging from 0 ("Not at all") to 10 ("extremely")

\section{Results}

Incident characteristics. The manipulation-check items confirmed that participants 
felt that the other person blamed them more, both overtly and privately, and that the other person would blame them more in the future, in the blamed than in the unblamed condition. Participants also rated self-accountability at significantly higher levels in the blamed condition despite instructions to report on incidents that were not their fault but scores were still well below the midpoint of the scale. There were no significant differences in how easy the two incidents were to recall or in how good an example of the specified incident was provided by the reported episode. Means and t values relating to all significant differences between blamed and unblamed conditions are presented in Table 2.

Emotions. The prediction that rated guilt would be higher in the blamed condition was supported. Similarly, ratings of the guilt-related adjective "remorse" were also significantly higher in this condition. The only other emotion item rated as significantly higher in the blamed condition was "scornful." Emotion items from the sympathy (sympathetic, pitying, and compassionate), hope (hopeful, optimistic), and interest (interested, fascinated) scales were all significantly higher in the unblamed condition, but there were no other significant differences. Of these emotion items and scales, only remorse showed significant positive correlations with guilt (blamed condition: $r(14)=.75, p=.002$; unblamed condition: $r(14)=.99, p<.001)$. The only other reliable correlation in either condition was a negative correlation of scornful in the blamed condition $(r(14)=-.67, p=$ $.008)$.

\section{Predictors of reported guilt in blamed condition. Having established that being} blamed induced higher levels of guilt, we explored which variables were associated with guilt intensity in the blamed condition using Pearson's correlations. With a sample of this size, coefficients needed to exceed .53 to be statistically significant.

The only appraisal dimension significantly associated with guilt according to this strict criterion was motivational relevance $(r(13)=.62, p=.019)$. As in the unreasonable 
blame condition of study 1 , ratings of self-accountability were only weakly related to guilt ( $r$ $(13)=.14, p=.623)$. Self-accountability was not significantly associated with any of the relational motivation variables either. By contrast, the relational motivation measures all showed significant or near-significant positive correlations with guilt (relationship repair: $r$ $(13)=.51, p=.062$; interpersonal emotion repair: $r(13)=.56, p=.038$; making amends: $r$ $(13)=.76, p=.002)$. Anticipated blame from the other was also reliably positively correlated with guilt $(r(13)=.63, p=.018)$.

We assessed whether variance in guilt could be accounted for fully in terms of motivational relevance, incongruence, and self-accountability as predicted by the Smith and Lazarus model. After controlling for all these appraisal components, desire to apologise was still reliably correlated with guilt $(r(9)=.69, p=.020) .^{5}$

Interrelations between effects of blame. In order to clarify what variables predicted the extent of the effect of the blame manipulation on guilt, we computed scores representing the difference between the blamed and unblamed conditions for all relevant variables for each participant. The only difference score reliably correlated with differences in guilt related to anticipated blame from other $(r(14)=.74, p=.002)$. None of the difference scores based on appraisal measures showed significant correlations with differences in guilt. The anticipated blame from other difference score remained a significant predictor of guilt even after controlling for motivational relevance, motivational congruence and self-accountability $(r$ (9) $=.81, p=.003)$. This latter finding is also consistent with the conclusion that rated appraisals did not fully explain the effects of the manipulation (as indexed by the same difference scores analysed in the repeated measures $t$ tests). Because of the limited size of the dataset and the within-participants design, more elaborate tests of mediation were not possible.

Examples of guilt without reported self-accountability. The above analyses strongly suggest that being blamed may lead to guilt independently of self-accountability. In order to 
determine what specific situations tend to lead to this kind of appraisal-emotion disjunction, we again searched our dataset for reported episodes of being blamed involving relatively higher ratings of guilt than of self-accountability. In order to ensure that these involved at least moderate levels of guilt, we restricted our search to participants rating guilt at or above the midpoint of the scale. Table 3 shows the three incidents associated with the maximal discrepancies between guilt and self-accountability based on these criteria.

\section{Discussion}

As predicted, guilt ratings were significantly higher for incidents in which participants were blamed for something that was not their fault than for incidents when they were not the target of someone else's blame. This effect was not associated with between-condition differences in self-accountability ratings but instead related to different levels of anticipated blame from the other. The association between anticipated blame difference scores remained significant even after controlling for differences in appraisal. This pattern of findings suggests that the impact of the blame manipulation on guilt was mediated by relational factors rather than appraisal factors.

Not all of our participants responded to blame from someone else with equivalent levels of guilt. The extent to which they reported this emotional reaction depended on motivations to repair the relationship with the other person. Indeed, desire to apologise was significantly associated with guilt even after controlling for self-accountability, motivational congruence, and motivational relevance. Thus, rated guilt does not seem to depend solely on reportable self-blame-related appraisals as implied by Smith and Lazarus (1993).

An alternative interpretation of the significant association between apology and guilt is that the former is a consequence rather than an antecedent of the latter. Indeed, the items are comparable to those used by other researchers to index action tendencies (e.g., Frijda, Kuipers, \& ter Schure, 1987) or "emotivations" (Roseman, 2001) that are associated with 
already activated emotions. Even according to this interpretation, the significant difference in reparatory relational motivations across conditions provides additional corroboration of the finding for the single-item guilt measure (see also footnote 3). Like guilt ratings, reports of the desire to apologise were not significantly related to self-accountability in the blamed condition, making a mediated causal path from self-accountability via guilt to apology unlikely. Further, the significant accountability-independent variance shared by guilt and apology would still confirm that this appraisal is not always the exclusive determinant of this emotion and its associated action tendencies.

Some of the specific examples of responses to blame from the other provided by participants confirm that guilt is possible in the absence of prior self-accountability appraisals. For some people at least, simply being blamed can lead to reports of guilt without any explicit acknowledgement that the self is actually to blame. As in study 1 , there was no specific request to generate examples of guilt, making it likely that participants' spontaneous reports of this emotion without any obvious justification reflected their actual experiences.

Nevertheless, we do not want to argue that self-accountability and self-blame can never lead to guilt or that people only feel guilty when others blame them. Clearly, there may be situations in which people privately conclude that they are responsible for some negative event and come to feel guilty for that reason. Study 3 attempted to disentangle the effects of self-blame and blame from others more systematically by varying both factors independently.

Study 3

Studies 1 and 2 demonstrated that guilt may arise as a result of other people's blame, and that under these circumstances this emotion is not always entirely dependent on selfblame. However, study 1 also showed that guilt was a more consistent reaction to blame from others when also accompanied by self-blame. This finding raises the question of whether self-blame makes an independent contribution to guilt in situations when there is no 
blame from others (e.g., private guilt in response to unobserved transgressions). The aim of study 3 was to assess the relative contributions of self-blame and blame from others in guilt across a wider range of situations than explored in the previous studies. In particular, participants reported on episodes where someone blamed them but they did not blame themselves (as sampled in studies 1 and 2), control situations where they were blamed by neither self nor other (as sampled in study 2), episodes when they were blamed by both self and other (as sampled in study 1), and also on episodes when they had blamed themselves but the other had not blamed them. Thus, our intention was to manipulate self-blame and blame from others orthogonally so that we might assess their independent and interactive effects. Our prediction was that manipulations of both self-blame and blame from others would influence guilt levels.

\section{Method}

Participants. Three male and 19 female undergraduate students at Oxford University aged between 20 and 22 took part during a practical class.

Design. The study employed a 2 X 2 factorial design with repeated measures on the two factors: self-blame (no self-blame vs. self-blame) and blame from other (unblamed vs. blamed).

Procedure. The questionnaire was headed: "Emotional responses to the misfortunes of others" and the instructions presented the study as involving possible differences in reactions to someone else's suffering. As in studies 1 and 2, no reference was made to guilt. Two versions of the questionnaire were prepared with the order of conditions counterbalanced. Each participant was asked to report on four separate incidents defined by the orthogonal combination of the self-blame and blame from other factors. In the self-blame, blamed condition, participants were asked to recall the most recent situation in which "something bad happened to someone close to you and you felt that they (justifiably) blamed you for it." In 
the no self-blame, blamed situation, participants were asked to recall a situation in which "something bad happened to someone close to you that was not a result of anything you had done (or not done), but that you still felt that they blamed you for." In the self-blame, unblamed condition, participants were asked to recall a situation in which "something bad happened to someone close to you as a result of something that you had done (or not done), but that you didn't feel that they blamed you for." Finally, in the no self-blame, unblamed (control) condition, participants were asked to recall a situation in which "something bad happened to someone close to you that was not a result of anything you had done (or not done), and that you didn't feel that they blamed you for."

Measures. For each incident, participants completed items concerning characteristics of the situation, appraisals, relational motivations, and emotions. All of these items were identical to those used in study 2. In order to keep the questionnaire to a manageable length, we excluded items concerning perceptions of the other person's sense of blame and accountability directed at the participant.

\section{Results}

Data quality. Data from items assessing the episode's ease of recall and correspondence to specifications were subjected to a multivariate 2 X 2 analysis of variance with repeated measures on both factors (self-blame and blame from others). There were no multivariate main effects but a significant multivariate interaction $(F(2,15)=7.07, p=$ $\left.0.007, \eta_{p}{ }^{2}=.49\right)$. This was reflected by significant univariate interactions for both items $\left(\right.$ Ease of recall $F(1,16)=13.40, p=0.002, \eta_{p}{ }^{2}=.46 ;$ Good example $F(1,16)=9.46, p=$ $\left.0.007, \eta_{p}{ }^{2}=.37\right)$. The unblamed no-self-blame situation was rated as significantly easier to recall $(M=6.35)$ and a better example of specifications $(M=7.29)$ than all other reported situations. By contrast, the blamed no-self-blame situation was rated as least easy to recall $(M=2.06)$ and the least good example $(M=4.71)$, although the differences were only 
significant in comparison to the unblamed no-self-blame condition and, for ease of recall rating, the blamed self-blame condition $(M=3.82)$. There were no significant effects on reports of how long ago the four kinds of incident had occurred.

Perceived blame. Data from items relating to whether the other person blamed the participant (overt blame, private blame, and anticipated blame from other) and the item assessing whether participants thought they actually were to blame, were together entered into a similar MANOVA. There were significant multivariate main effects of both self-blame $\left(F(4,14)=47.78, p<.001, \eta_{p}^{2}=.93\right)$ and blame from other $\left(F(4,14)=68.19, p<.001, \eta_{p}^{2}\right.$ $=.95)$, and a near significant multivariate interaction effect $\left(F(4,14)=2.83, p=.065, \eta_{p}{ }^{2}=\right.$ .45). Univariate tests revealed a significant main effect of blame from other on overt blame $\left(F(1,17)=99.66, p<.001, \eta_{p}^{2}=.85\right)$ but no other significant effects. As predicted, participants in the blamed conditions rated overt blame from other as significantly higher $(M$ $=5.97)$ than participants in the unblamed condition $(M=0.28)$. Similarly, participants rated the extent to which the other privately blamed them as significantly higher in the blamed $(M$ $=7.58)$ than the unblamed condition $\left(M=1.53, F(1,17)=270.75, p<.001, \eta_{p}{ }^{2}=.94\right)$. On this measure, however, there was also a significant main effect of the self-blame manipulation $\left(F(1,17)=35.63, p<.001, \eta_{p}{ }^{2}=.68\right)$ with participants reporting that the other person privately blamed them to a significantly greater extent in the self-blame $(M=5.61)$ than in the no-self-blame condition $(M=3.50)$. A similar pattern of effects was obtained on the anticipated blame measure, but here in addition to the main effects of blame from other $(F$ $\left.(1,17)=59.12, p<.001, \eta_{p}{ }^{2}=.78\right)$ and self-blame $\left(F(1,17)=19.30, p<.001, \eta_{p}{ }^{2}=.53\right)$, there was also a significant interaction $\left(F(1,17)=5.32, p=.034, \eta_{p}{ }^{2}=.24\right)$. When there was no self-blame, anticipated blame was much higher in the blamed than in the unblamed condition (where it was at zero). However, in the self-blame condition, blame from other had less effect on anticipated blame (see Figure 1). 
The manipulation check for the self-blame manipulation assessing perceived actual blame showed significant univariate main effects for both self-blame $(F(1,17)=198.36, p<$ $\left..001, \eta^{2}=.92\right)$ and blame from other $\left(F(1,17)=9.12, p=.008, \eta^{2}=.35\right)$. As predicted, mean actual blame was higher in the self-blame $(M=7.17)$ than in the no self-blame condition $(M=.64)$. However, blame from other also significantly enhanced perceptions of actual blame (unblamed $M=3.17$, blamed $M=4.64$ ). There was no significant univariate interaction for this measure. In summary, our attempt to manipulate self-blame and blame from other independently was not entirely successful. Situations with higher blame from other tended also to be associated with higher self-blame and situations with higher selfblame tended also to be associated with higher anticipated and private blame from other.

Guilt. Guilt ratings were subject to a significant main effect of self-blame $(F(1,17)=$ $\left.108.19, p<.001, \eta_{p}{ }^{2}=.86\right)$ and a significant interaction $\left(F(1,17)=13.87, p=.002, \eta_{p}{ }^{2}=\right.$ $.45)$. Guilt ratings were higher in the self-blame condition $(M=6.33)$ than in the no-selfblame condition $(M=1.17)$. Further, blame from others had little impact on guilt in the selfblame condition but increased guilt significantly in the no-self-blame condition. This last effect replicates the central finding of study 2. Means illustrating the significant interaction are presented in Figure 1. As in the earlier studies, the relatively low mean level of guilt reported in the no-self-blame, blamed condition belies the fact that several participants reported moderate to strong guilt. Examples of reported situations associated with high levels of guilt but low levels of self-accountability are presented in Table 3.

Relational motivations. Participants reported stronger desires to put things right with the other person (relationship repair) in the self-blame $(M=7.83)$ than in the no-self-blame condition $\left(M=5.25, F(1,17)=23.71, p<.001, \eta_{p}{ }^{2}=.58\right)$. However, this effect was qualified by a near-significant interaction with blame from other $(F(1,17)=4.29, p=.054$, $\left.\eta_{p}{ }^{2}=.20\right)$. In the self-blame condition, blame from other made almost no difference to 
motivations to put things right with the other person. However, in the no-self-blame condition, blame from other significantly increased motivations to repair the relationship. The same pattern of significant effects was obtained for the desire to apologise variable (selfblame $F(1,17)=180.50, p<.001, \eta_{p}{ }^{2}=.58$; interaction $F(1,17)=5.05, p=.038, \eta_{p}{ }^{2}=$ .23). Again, participants reported stronger desires to apologise in the self-blame than in the no-self-blame condition, and again the difference between the blamed and unblamed conditions was smaller and non-significant in the self-blame condition, and larger and significant in the no-self-blame condition. Note that this pattern of findings for relationship repair and desire to apologise paralleled the pattern of effects on guilt and anticipated blame ratings. For the interpersonal emotion repair variable, however, the only significant effect was a main effect of blame from other $\left(F(1,17)=8.90, p=.008, \eta_{p}{ }^{2}=.34\right)$. Participants reported higher motivation to make the other person feel better when not blamed $(M=7.86)$ than when blamed $(M=6.33)$.

Appraisals. Participants rated themselves as significantly more accountable $(M=$ 7.28) and the other as significantly less accountable $(M=4.15)$ in the self-blame than in the no-self-blame condition (self-accountability $M=.88$, other-accountability $M=6.71$; self accountability $F(1,16)=133.87, p<.001, \eta_{p}{ }^{2}=.89$; other-accountability $F(1,16)=15.36$, $\left.p=.001, \eta_{p}{ }^{2}=.49\right)$. Like perceived actual blame ratings, self-accountability ratings were also significantly influenced by the blame from other manipulation $(F(1,16)=7.28, p=$ $\left..016, \eta_{p}{ }^{2}=.31\right)$. Ratings of self-accountability were higher in the blamed $(M=4.74)$ than in the unblamed condition $(M=3.41)$. None of the appraisal measures showed significant interaction effects.

Predictors of reported guilt. In the blamed, no-self-blame condition, none of the selfblame-related appraisal dimensions were significantly correlated with guilt (motivational relevance: $r(20)=.14, p=.533$; motivational congruence: $r(20)=.17, p=.449$; self- 
accountability: $r(20)=.33, p=.143)$, and only motivational relevance showed any significant associations with relational motivation variables. However, the relational motivation measures all showed near-significant positive correlations with guilt (relational repair: $r(20)=.41, p=.069$; interpersonal emotion repair: $r(20)=.42, p=.060$; desire to apologise: $r(20)=.43, p=.051)$. Controlling for self-accountability did not reduce these associations (relational repair: $r(18)=.54, p=.013$; interpersonal emotion repair: $r(18)=$ $.47, p=.038$; desire to apologise: $r(20)=.53, p=.016)$, and all three remained significant or near-significant after controlling for self-accountability, motivational congruence and motivational relevance together (relational repair: $r(16)=.54, p=.022$; interpersonal emotion repair: $r(16)=.43, p=.076$; desire to apologise: $r(16)=.54, p=.020$ ).

Self-accountability was correlated significantly with guilt only in the unblamed, selfblame condition $(r(19)=.71, p=.001)$. All three relational motivation variables were also correlated significantly with guilt in this condition (relational repair: $r(19)=.56, p=.013$; interpersonal emotion repair: $r(19)=.54, p=.016$; desire to apologise: $r(19)=.68, p=$ $.001)$

Interrelations between effects of blame in the no-self-blame condition. Replicating the analyses conducted on study 2's data, we assessed whether intra-individual differences in guilt between the blamed and unblamed no-self-blame conditions were associated with differences in appraisals and relational motivations. None of the correlations were significant, but desire to apologise difference scores showed a near-significant positive correlation with guilt difference scores $(r(20)=.39, p=.077)$, which remained at a similar level even after controlling for self-accountability $(r(19)=.38, p=.098)$ or for motivational relevance, motivational congruence and self-accountability difference scores $(r(17)=.36, p$ $=.164)$. As before, the sample size and within-participants design combine to make more sophisticated tests of mediation unworkable. 


\section{Discussion}

Study 3's results again confirm that blame from someone else can lead to guilt even when people do not blame themselves. However, the self-blame manipulation also made an independent contribution to guilt leading to more consistent reports of intense guilt than blame from others alone. When participants blamed themselves but did not feel blamed, guilt was also rated at increased levels supporting the predictions of appraisal theory (e.g., Smith \& Lazarus, 1993).

Although self-blame is clearly an influential factor in many instances of guilt, the present results again confirm that it does not fully explain all instances of guilt in response to blame from others. Indeed, results of the correlational analyses make appraisals relating to self-blame unlikely mediators of some of the significant effects reported here. In particular, self-accountability difference scores were not significantly correlated with differences in guilt due to the blame manipulation in the no-self-blame condition. Further, relational motivations were again significant predictors of guilt in the unblamed condition even after controlling for self-blame related appraisals. Finally, self-accountability was only significantly correlated with guilt in the blamed, self-blame condition and not in any other condition. Thus, the association between guilt and self-blame appraisals seems to vary depending on context (cf. Nezlek, Vansteelandt, Van Mechelen, \& Kuppens, 2008).

As in study 2 , it is possible that the relational motivation variables index consequences rather than antecedents of guilt. However, even in this case, differences in these measures between blamed and unblamed conditions provide further corroboration of the effects on the guilt item. Relational motivation variables also showed no significant associations with self-accountability in the blamed, no self-blame condition again making it unlikely that guilt mediated an effect of this appraisal on guilt-related action tendencies. 
The results of study 3 would be clearer if we had succeeded in manipulating selfblame and blame from others in perfect independence of one another. However, the intercorrelation of these variables in most everyday situations made this practically impossible. When other people blame you for something, they often have some reason for doing so and you too are often aware of this reason. Correspondingly, it is relatively unusual for others not to blame you for actions (or inactions) that you personally find blameworthy (as evidenced by the anticipated and private blame ratings here). The interconnections between these two variables in life outside the laboratory may lead to common misattributions about the genuine causes of guilt when someone else blames you for something.

\section{General Discussion}

Based on a social-relational approach (Parkinson, Fischer, \& Manstead, 2005) and previous investigations of unreasonable emotions (Parkinson, 1999), we predicted that exposure to blame from close others would sometimes lead to guilt in the absence of selfblame. Three studies, using diaries and retrospective questionnaires confirmed this prediction. Further, studies 2 and 3 showed that social-relational variables accounted for a significant proportion of the variance in guilt even after controlling for self-blame-relevant appraisals, and that the effects of the blame from other manipulation were related to effects on relational rather than appraisal variables (in no-self-blame conditions). Taken together, the findings also suggest that self-blame-related appraisals are not a necessary condition for the experience of this emotion, and that motives for repairing relationships may often represent a reliable independent predictor (or correlate) of guilt. Indeed, several participants in all three studies explicitly reported guilt in situations where someone else blamed them but they did not feel personally to blame. The overall pattern of results is consistent with an interpersonal analysis that sees guilt as a strategy for putting right relationships where there is 
a perceived (but not necessarily genuine) slight (e.g., Baumeister et al., 1994).

As we expected, being blamed did not consistently lead to emotional reactions of guilt across all sampled situations and participants. Indeed, our results suggest that spontaneous reports of guilt in response to unreasonable blame may be relatively uncommon, perhaps partly because participants find it hard to interpret, explain, or justify them. The question of how commonly such reactions occur in everyday life should be addressed using more rigorous time-sampling methods. Even if guilt turns out to be a highly infrequent response to unreasonable blame from others, we believe that its occurrence is still important to our theoretical understanding of guilt in interpersonal contexts.

The present findings show that the extent of guilt experienced depended on current motives to repair the relationship. Another challenge for future research is to specify more precisely the circumstances under which another's blame leads to our own guilt. Our intuition is that blame may be conveyed in several different ways some of which lead more consistently to guilty reactions than others. However, the nature of the emotional outcome probably also depends on the way that the blamer responds to the developing reactions of the blamed person as part of a co-regulated process (cf. Fogel et al., 1992). Relationship characteristics and individual differences may also help to determine susceptibility to differential emotional effects of being blamed. Indeed, future research should address the issue of whether general guilt-proneness (e.g., Tangney \& Dearing, 2002) or more specific emotional tendencies predispose participants to react with guilt to these particular interpersonal situations.

All three of these studies used relatively small samples, meaning that some moderately sized effects were non-significant. It would therefore be wrong to conclude that self-accountability played no role in guilt causation in the sampled situations where participants were exposed to unreasonable blame from another person. However, the fact 
relational motivations were significant predictors of guilt even under conditions of limited statistical power, and even after controlling for self-accountability in study 2 supports the claim that other factors can sometimes have an independent influence on this emotion. Further, the demonstration that some people sometimes report guilt even when they do not feel personally accountable for what has happened to someone else does not require a large sample.

Although the present findings suggest that another person's blame can play an important role in the activation and maintenance of guilty reactions, the results of study 3 also confirm appraisal theory's prediction that self-blame can also be a strong predictor of this emotion. Indeed, previous research has often shown consistent moderate positive correlations between reported self-blame-related appraisals and self-reported guilt (e.g., Bennett, Lowe, \& Honey, 2003; Frijda, Kuipers, \& ter Schure, 1989; Smith \& Lazarus, 1993; Tracy \& Robins, 2006), and the present investigations confirm this association. One reason why self-blame might contribute to guilt is that it undermines the motivation to actively contest another's blame (e.g., using counter-anger or contempt). However, there are also clearly situations in which people privately conclude that they are responsible for some negative event and come to feel guilty for that reason. An interesting question for future research concerns whether these self-blame-dependent instances of guilt precede guilt in response to blame from others in ontogeny or whether they derive from developmentally prior responses to blame from caregivers, whose values are subsequently internalised (see Parkinson, 2007). In either case, it seems important to distinguish between the different possible causal routes to guilt at a theoretical and empirical level.

Even when guilt is originally activated by blame from another person, it may often be the case that self-blame arises at some point as a consequence of exposure to this interpersonal blame. Some of the dissociations between appraisal and guilt reports noted in 
the present research may reflect the failure of the questionnaire items to detect self-blame about matters not directly related to the incident of most direct concern to the blamer. For example, guilt may partly depend on the sense that one ought to have been able to protect someone close from the source of his or her distress, rather than the perception that one is actually to blame for what has happened to this other person. It is also possible that selfblame may be activated at a non-conscious level by blame from others or may even be explicitly repressed. Clearly neither form of appraisal would register on the self-report measures used here and elsewhere. The plausibility of these alternative accounts of guilt in response to blame from others can only be assessed properly by refining our conceptualisation, manipulation and operational measures of the relevant appraisal processes (see also Parkinson, 1997; Scherer, 2001).

Our finding that Smith and Lazarus's (1993) self-accountability measure does not show consistently strong relations to guilt under all circumstances also does not rule out the influence of other similar variables relating to personal responsibility or internal, unstable, and controllable attributions (e.g., Tracy \& Robins, 2006) when accountability-guilt associations are relatively weak. However, previous research reviewed in the Introduction (e.g., Kroon, 1998, see Frijda, 1993) suggests that participants often report guilt about events that they do not believe they have caused and for which they feel no responsibility. In our view, guilt may sometimes emerge as an interpersonal adjustment to another person's blame in the absence of any appraisal of personal causation, responsibility, or accountability. However, these more articulated appraisals are often quickly recruited as part of the developing guilty reaction (see Frijda, 1993; Parkinson, Fischer, \& Manstead, 2005). Although guilt is clearly often a self-conscious emotion (e.g., Tangney \& Dearing, 2002; Tracy \& Robbins, 2006), we believe that attunement to relations between self and other may precede this self-consciousness as the emotion develops (in real time as well ontogeny, cf. 
Draghi-Lorenz, Reddy, \& Costall, 2001).

Our proposals about the dynamics of guilt activation bear some relation to existing accounts of the related "self-conscious" emotion of shame (e.g., Tangney \& Dearing, 2002; Tracy \& Robins, 2006). Shame is already acknowledged to be a possible reaction to threats to reputation, and public blaming may sometimes constitute precisely such a threat.

However, we think it unlikely that our participants were misreporting shame responses as guilt in the present study for three reasons. First, most of the reported occasions for guilt in response to another's blame occurred in private settings in which no-one else would have been aware of the accusation being made. Thus, there was no real threat to public reputation or "face." Second, the effects of the blame manipulation on reparatory relational motivation items are not compatible with the withdrawal-related action tendencies thought to be associated with shame (see Tangney \& Dearing, 2002). Third, more recent research in our laboratory using similar procedures but incorporating a specific shame item among the emotion measures failed to reveal any significant effect of being blamed on shame.

A recurrent limitation of research into guilt is its reliance on self-reports. ${ }^{5}$ Since there seems to be no single pattern of dynamic nonverbal conduct that uniquely indicates guilt (see Zahn-Waxler \& Kochanska, 1990), investigators often have to take participants' word for it when assessing the extent of this emotion. So do our findings really tell us anything about how guilt itself is produced or are they instead merely a reflection of people's implicit and explicit representations of the meaning of the English-language term "guilt"? ${ }^{6}$ For example, it might be argued that all we have done here is clarified the prototypic meanings of this Western concept (cf. Russell, 2003). If so, we have shown that despite what dictionaries and appraisal theorists may say, blaming oneself is not a defining feature of this concept as used in everyday life.

However, we believe that our results have deeper implications concerning real-time 
emotional processes as well as emotion representations. Although there is some apparent disparity in the reported characteristics and causes of guilt, the functional core of this emotion as a mode of relational repair in response to certain forms of accusation and blame still remains. Saying that you feel guilty is more than a loose characterization of certain experiential and circumstantial facts; it is a claim about the state of your relationship that expresses and communicates a specific kind of appraisal and action readiness with broadly predictable interpersonal consequences. Apprehension of these relational patterns allows us to derive a prototypic representation, not vice versa.

\section{Conclusions}

A typical aspect of guilt experiences is feeling bad about something that we have done or not done. Indeed, the presence of such evaluative feelings may be the main reason we categorize our experience as a proper example of guilt. But what leads us to evaluate our own actions (or inactions) negatively in the first place? According to some versions of appraisal theory, what activates the guilt process is the appreciation that we are personally to blame for a motivationally incongruent event. Although this is one of the possible routes to experiencing guilt, the present results suggest that self-blame appraisals are not a necessary precondition for this emotion. Instead, we found that guilt often depends on the perception that other people are blaming you for having done (or not done) something, even when you do not actually feel blameworthy. The unpleasant feelings that often arise in reaction to accusations constitute at least one form of what people describe as "guilt," and perhaps even the original basis for experiencing this emotion. Future research should address the circumstances under which another person's blame leads to guilt rather than anger or contempt. Our intuition is that the nature of the current relationship with the other is an important factor in determining the emotional reaction, and that the blamer's presented emotions also make a difference to our level of guilt. 


\section{Footnotes}

1. These emotion items were selected to be face-valid reactions when blaming someone else or being blamed. Apart from the "guilty" item, their primary purpose was to disguise the study's specific focus on this emotion, and because the questionnaire needed to be kept to a manageable length to facilitate diary-keeping, there was no attempt to sample the full possible range of emotional reactions to being blamed.

2. The items were: afraid, angry, annoyed, apathetic, bored, challenged, compassionate, contemptuous, detached, determined, disdainful, downhearted, eager, fascinated, frightened, guilty, happy, hopeful, interested, intrigued, joyful, light-hearted, optimistic, pitying, regretful, relieved, remorseful, resentful, resigned, sad, scared, scornful, sorrowful, and sympathetic.

3. Although Smith and Lazarus combined these items into scales, the present research assesses emotions at the item level. The main reason for this decision is that two of the items from Smith and Lazarus's guilt scale assess qualitatively different emotions of "guilt" and "regret." Indeed, unlike guilt, Berndsen et al. (2004) found that regret was more responsive to intrapersonal than interpersonal considerations. At any rate, analyses based on the three-item guilt measure revealed the same difference in guilt between the blamed and unblamed condition in this study. Other investigators have also included other items relating to appraisals or action tendencies in their self-report measures of this emotion (e.g., Tangney \& Dearing, 2002). Such measures presuppose precisely those connections between variables that the present studies call into question. Nonetheless, our relational motivations measures are similar to previous measures of action tendencies, thus allowing us to demonstrate that these (as well as guilt itself) are sometimes dissociated from self-blame appraisals. 
4. The change from a 9-point scale to an 11-point scale was made to ensure consistency with Smith and Lazarus's appraisal items, which use this response format.

5. In recent research, we have corroborated the self-report findings reported here using blamers' third-person reports of perceived guilt in the target of blame. The new study also used a multi-item measure of guilt instead of the single item used in the present study, and found similar effects to those reported here.

6. A reviewer of a previous version of this manuscript pointed out that people sometimes say that they are guilty when acknowledging some wrongdoing even when there is no genuinely emotional reaction. However, the guilt ratings collected in all three studies presented in this paper were given in response to explicit requests for reports of emotional reactions and the fact that other obviously emotional items were presented before and after the guilt item reinforced this instruction. 


\section{References}

Barrett, K. C. (1995). A functionalist approach to shame and guilt. In J. P. Tangney \& K. W. Fischer (Eds.), Self-conscious emotions (pp. 25-63). New York: Guilford Press.

Baumeister, R. F., Stillwell, A. M., \& Heatherton, T. F. (1994). Guilt: An interpersonal approach. Psychological Bulletin, 115, 243-267.

Baumeister, R. F., Stillwell, A. M., \& Heatherton, T. F. (1995). Personal narratives about guilt: Role in action control and interpersonal relationships. Basic and Applied Social Psychology, 17, 173-198.

Bennett, P., Lowe, R., \& Honey, K. L. (2003). Appraisals, core relational themes, and emotions: A test of the consistency of reporting and their associations. Cognition and Emotion, 17, 511-520.

Berndsen, M., van der Pligt, J., Doosje, B., \& Manstead, A. S. R. (2004). Guilt and regret: The determining role of interpersonal and intrapersonal harm. Cognition and Emotion, $18,55-70$.

Draghi-Lorenz, R., Reddy, V., \& Costall, A. (2001). Re-thinking the development of "nonbasic" emotions: A critical review of existing theories. Developmental Review, 21, 263-304.

Ekman, P., \& Friesen, W. V. (1982). Felt, false, and miserable smiles. Journal of Nonverbal Behavior, 6, 238-252.

Emde, R., Johnson, W. F., \& Easterbrooks, A. (1987). The dos and don'ts of early moral development: Psychoanalytic tradition and current research. In J. Kagan \& S. Lamb (Eds.), The emergence of morality (pp. 245-276). Chicago: University of Chicago Press.

Fogel, A., Nwokah, E., Dedo, J. Y., Messinger, K., Dickson, K. L., Matusov, E, \& Holt, S. A. (1992). Social process theory of emotion: A dynamic systems approach. Social Development, 1, 122-142.

Frijda, N. H. (1993). The place of appraisal in emotion. Cognition and Emotion, 7, 357-387.

Frijda, N. H., Kuipers, P., \& ter Schure, E. (1989). Relations among emotion, appraisal, and emotional action readiness. Journal of Personality and Social Psychology, 57, 212 228.

Hoffman, M. L. (1982). Development of prosocial motivation: Empathy and guilt. In N. Eisenberg (Ed.), The development of prosocial behavior (pp. 281-313). New York: Academic Press.

Kuppens, P., Van Mechelen, I., Smits, D. J. M., \& De Boeck, P. (2003). The appraisal basis of anger: Specificity, necessity and sufficiency of components. Emotion, 3, 254-269.

Lazarus, R. S. (1991). Emotion and adaptation. New York: Oxford University Press.

Millar, K. U., \& Tesser, A. (1988). Deceptive behavior in social relationships: A consequence of violated expectations. Journal of Psychology, 122, 263-273.

Nezlek, J. B., Vansteelandt, K., Van Mechelen, I., \& Kuppens, P. (2008). Appraisal-emotion relationships in everyday life. Emotion, 8, 145-150. 
O'Malley, M. N., \& Greenberg, J. (1983). Sex differences in restoring justice: The down payment effect. Journal of Research in Personality, 17, 174-185.

Parkinson, B. (1997). Untangling the appraisal-emotion connection. Personality and Social Psychology Review, 1, 62-79.

Parkinson, B. (1999). Relations and dissociations between appraisal and emotion ratings of reasonable and unreasonable anger and guilt. Cognition and Emotion, 13, 347-385.

Parkinson, B. (2001). Putting appraisal in context. In K. R. Scherer, A. Schorr, \& T. Johnstone (Eds), Appraisal processes in emotion: Theory, research, application (pp. 173-186). Oxford University Press.

Parkinson, B. (2007). Getting from situations to emotions: Appraisal and other routes. Emotion, 7, 21-25.

Parkinson, B., Fischer, A. H., \& Manstead, A. S. R. (2005). Emotion in social relations: Cultural, group, and interpersonal processes. Philadelphia, PA: Psychology Press.

Parkinson, B. \& Manstead A. S. R. (1992). Appraisal as a cause of emotion. In M. S. Clark (Ed.), Review of personality and social psychology 13: Emotion (pp. 122-149). Newbury Park, CA: Sage.

Parkinson, B., Roper, A., \& Simons, G. (in press). Appraisal ratings in diary reports of reasonable and unreasonable anger. European Journal of Social Psychology.

Raudenbush, S. W., \& Bryk, A. S. (2002). Hierarchical linear models: Applications and data analysis methods (2nd edition). Thousand Oaks, CA: Sage.

Roseman, I. J. (2001). A model of appraisal in the emotion system: Integrating theory, research, and applications. In K. R. Scherer, A. Schorr, \& T. Johnstone (Eds.), Appraisal processes in emotion: Theory, methods, research (pp. 68-91). London: Oxford University Press.

Russell, J. A. (1987). Comments on articles by Frijda and by Conway and Bekerian. Cognition and Emotion, 1, 193-197.

Scherer, K. R. (2001). Appraisal considered as a process of multilevel sequential checking. In K. R. Scherer, A. Schorr, \& T. Johnstone (Eds.), Appraisal processes in emotion: Theory, methods, research (pp. 91-120). London: Oxford University Press.

Smith, C. A., \& Lazarus, R. S. (1993). Appraisal components, core relational themes, and the emotions. Cognition and Emotion, 7, 233-269.

Tangney, J. P., \& Dearing, R. L. (2002). Shame and guilt. New York, NY: Guilford Press.

Tracy, J. L., \& Robins, R. W (2004). Putting the self into self-conscious emotions: A theoretical model. Psychological Inquiry, 15, 103-125.

Tracy, J. L., \& Robins, R. W. (2006). Appraisal antecedents of shame and guilt: Support for a theoretical model. Personality and Social Psychology Bulletin, 32, 1339-1351.

Zahn-Waxler, C, \& Kochanska, G. (1990). The origins of guilt. In R. A. Thompson (Ed.), The Nebraska symposium on motivation 1988: Socioemotional development (Vol. 36: pp. 182-258). Lincoln: University of Nebraska Press. 


\section{List of Figures}

Figure 1: Mean scores for dependent variables showing significant interaction effects in Study 3. 

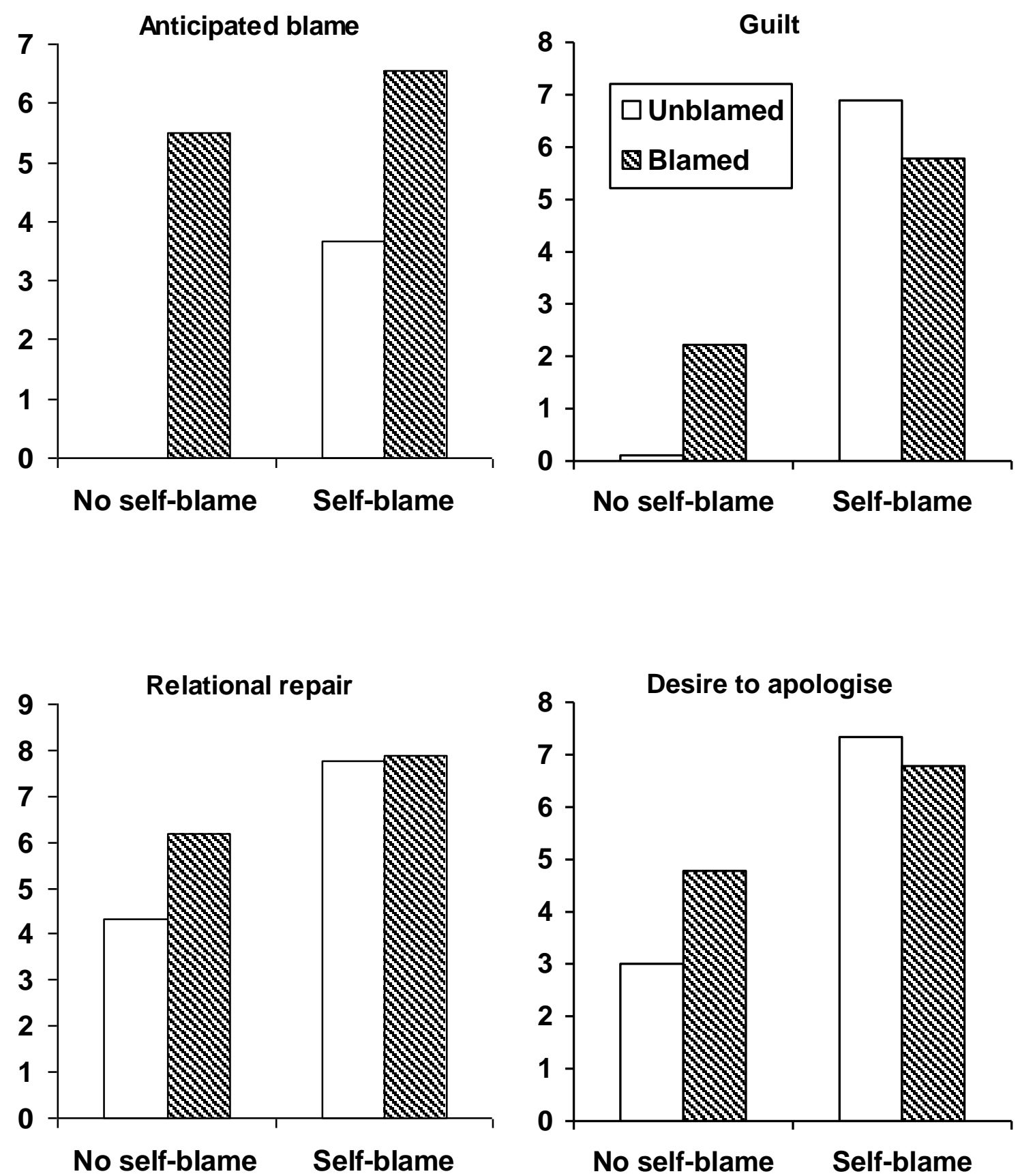
Table 1

Occasions for Guilt Associated with Low Self-Blame in Study 1

\begin{tabular}{lcc}
\hline $\begin{array}{l}\text { Incident description } \\
\text { Organising a social but was informed by someone that I may not } \\
\text { be allowed the plans I have. }\end{array}$ & $\begin{array}{c}\text { Guilt } \\
(1-9)\end{array}$ & $\begin{array}{c}\text { Self- } \\
\text { blame } \\
(1-9)\end{array}$ \\
$\begin{array}{l}\text { I had to make everyone change the date of a society committee } \\
\text { meeting because I was busy. }\end{array}$ & 7 & 2 \\
$\begin{array}{l}\text { Guy at church kept telling me how I should do more to help at } \\
\text { CU. Felt like I was being blamed or accused. }\end{array}$ & 9 & 4 \\
\hline
\end{tabular}


Table 2:

Significant Differences Between Blamed and Unblamed conditions in Study 2

\begin{tabular}{|c|c|c|c|c|c|}
\hline & & $\begin{array}{c}\text { Blamed } \\
\text { Mean }(S D)\end{array}$ & $\begin{array}{l}\text { Unblamed } \\
\text { Mean }(S D)\end{array}$ & $t$ & $p$ \\
\hline \multirow{3}{*}{$\begin{array}{l}\text { Perceptions of } \\
\text { blame from } \\
\text { other }\end{array}$} & $\begin{array}{l}\text { Other's overt } \\
\text { blame }\end{array}$ & $7.14(1.96)$ & $0.00(0.00)$ & 13.67 & $<.001$ \\
\hline & $\begin{array}{l}\text { Other's private } \\
\text { blame }\end{array}$ & $7.36(1.82)$ & $0.57(1.02)$ & 15.62 & $<.001$ \\
\hline & $\begin{array}{l}\text { Anticipated } \\
\text { blame from other }\end{array}$ & $5.71(2.33)$ & $0.36(0.74)$ & 8.33 & $<.001$ \\
\hline \multirow[t]{6}{*}{ Emotions } & Guilt (item) & $3.79(2.29)$ & $0.29(0.83)$ & 5.05 & $<.001$ \\
\hline & Remorse (item) & $2.57(2.68)$ & $0.43(1.34)$ & 2.56 & .024 \\
\hline & Scornful (item) & $1.50(2.03)$ & $0.54(0.33)$ & 2.77 & .016 \\
\hline & Sympathy (scale) & $2.93(2.59)$ & $6.43(1.10)$ & 4.81 & $<.001$ \\
\hline & Hope (scale) & $1.43(2.54)$ & $3.43(2.62)$ & 3.50 & .004 \\
\hline & Interest (scale) & $1.07(1.65)$ & $3.10(2.73)$ & 2.77 & .016 \\
\hline $\begin{array}{l}\text { Appraisal } \\
\text { dimensions }\end{array}$ & $\begin{array}{l}\text { Self- } \\
\text { accountability }\end{array}$ & $3.50(1.74)$ & $0.57(1.22)$ & 5.33 & $<.001$ \\
\hline $\begin{array}{l}\text { Relational } \\
\text { motivations }\end{array}$ & $\begin{array}{l}\text { Relationship } \\
\text { repair }\end{array}$ & $7.36(2.76)$ & $3.21(3.56)$ & 4.00 & .002 \\
\hline
\end{tabular}


Table 3

Occasions for Guilt Associated with Low Self-accountability in Study 2

\begin{tabular}{l}
$\begin{array}{l}\text { Incident description } \\
\begin{array}{l}\text { Guilt } \\
(0-10)\end{array}\end{array} \quad \begin{array}{c}\text { Self- } \\
\text { account- } \\
\text { ability } \\
(0-10)\end{array}$ \\
\hline $\begin{array}{l}\text { I promised not to speak to someone who my friend fancied. } \\
\text { Unfortunately this person approached me and my friend saw us } \\
\text { together and thought I had gone back on my word and initiated a } \\
\text { conversation. }\end{array}$ \\
$\begin{array}{l}\text { I got together with my boyfriend who is the closest friend of } \\
\text { someone else I know. This second person felt that I had stolen his } \\
\text { best friend away. }\end{array}$ \\
$\begin{array}{l}\text { I had said I couldn't take part in a sports event. My friend (team } \\
\text { captain) had forgotten. She had to find a substitute at the last } \\
\text { minute so was annoyed }\end{array}$ \\
\hline
\end{tabular}


Table 4

Occasions for Guilt Associated with Low Self-accountability in Study 3

Incident description

Guilt Self-

(0-10) account-

ability

(0-10)

My brother confessed to me how he felt our parents were more proud of me than him ... He felt very upset and bad about his own recent failings -- being kicked out of Uni. I had never been aware he felt that way.

My sister's camera was dropped on the floor and the expensive lens was broken. I was passing it to her at the time. She dropped it but blamed it on me.

Person who used to be best friend became somewhat separated from my group of friends, because I made new friends -- mainly because she hung around with people out of school, e.g., her boyfriend. 